\title{
釀造 研觉
}

昭 和 26 年度

\section{Diacetyl に關する研究（第三報） \\ アルュール醪中の Diacetyl について}

花井四 郎. 山田正一

(昭和 26 年 8 月 7 日受理)

アルコール璒中に Diacetyl の存在することは連續式蒸溜機代於て不純物アルコールとして除去されるる のの5ちに黄色成分として含有していることで知られているが，之がアルコール製品中えの移行は所霄つる り香の原因として非常に嫌われる。そして醪中に生成される Diacetyl は一般に腐敗醪に多いとされている のみで碓たる㸴究はなされていない。

普通 Diacetyl は aerogenes group 屬する細菌が acetoin きつくり，之が酸化化基因する三次生產物 とされているが, acetoin 1),2) については Neuberg の3) Carboligase の破究て酵将るつくり得るし, 又ある種の Rhizopus 屬) がつくることも最还報告せ方れ，更に先の報告(5) に於て酵母の純粹培養液中に微量の DiacetyI が檢出されている點より考えあわせても，健全な酸に於いても acetoin の酸化に低る Diacetyl の生成が汸

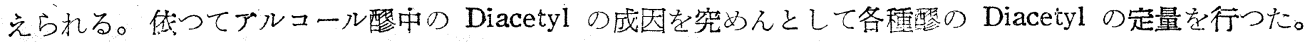

先ずVan Niel 法の Diacetyl 定量條件を求めるに溶液にアルコール汸: 70\% 女る事は一向に差支無いが

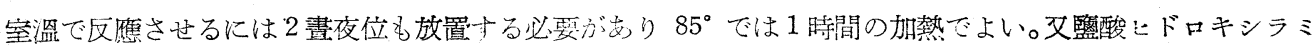
ンの濃度は溶液で $1 \%$ である事を必要條件とはせ㸚が濃厚の方がよい。

仕込法の異るアルコールもろ久中の Diacetyl 生成量は 0 0.00128\% 11 種本均 $0.000538 \%$ であつて酸 生成量が多かつたものが必ずしも多く生產されたとは見られなからた。何もろ又から分離した 14 種の菌類 につきその發育狀態を調べ培盖液中に生淛されるアセトイン系物質の檢出を行つた。

\section{實驗}

\section{Van Niel 法に依る Diacetyl 定量修件の再祫討}

Diacetyl の定量には一般にVan Niel 法6) が用いられているが，Ni-Dimethylglyoxime をつくる塨合，

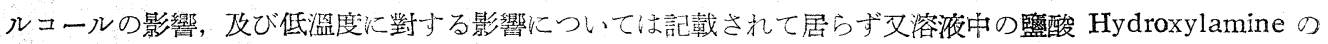
漘度が $1 \%$ になるように報告 ${ }^{7}$ されているため, 醪溜液中の Diacetyl 定量に際しそれらの影響を檢討した。

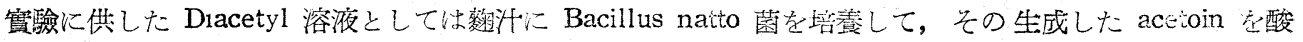
化, 蒸溜, 抽出したものにつき行つた。

\section{(1) アルコール及溫度の影響}

Diacetyl 液中の アルコール濃度\%

70

70

40

40

0

0

0
定 舅: 條

30

85

30

85

30

85

10
24

1

24

1

24

1

48
表

Ni-Dimethyl. 栖準を 100 とした glyoxime mg 場合の比䈞

67.2

100.5

69.6

65.8

104.1

$100 \cdot 0$

105.2

70.5

65.2

66.8

97.6

100.0

65.4

97.9 


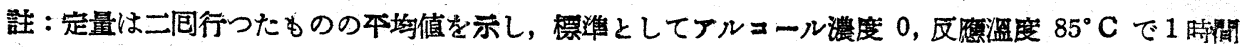
のものとした。

（2）液量に對する鹽酸 Hydroxylamine の濃度の影響

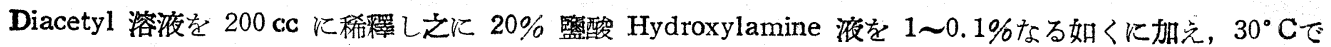
48 時間作用させた後, 定量した。

$$
\text { 第 } 2 \text { 表 }
$$

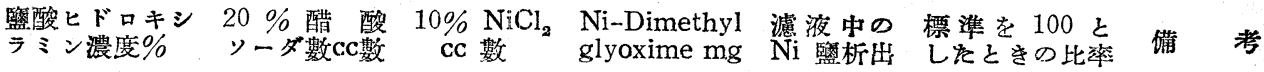

\begin{tabular}{|c|c|c|c|c|c|c|}
\hline 1 & 10 & 10 & 60.6 & 析出せぬるのある & $100 \cdot 0$ & 滤液は濃縮し \\
\hline 1 & 5 & 2 & 60.3 & & 99.5 & て析出するNi \\
\hline 0.5 & 10 & 5 & 61.4 & " & 101.5 & 盤を加える。 \\
\hline 0.5 & 5 & 2 & 59.2 & 析出する & 97.7 & \\
\hline 0.1 & 10 & 2 & 59.7 & " & 98.4 & \\
\hline 0,1 & 5 & 2 & 56.9 & " & 93.9 & \\
\hline
\end{tabular}

第一，第二表より Diacetyl 定量の場合 Van Niel の決定した條件と比較してアルコール濃度は定量に特 に影響を與えないが，低溫の場合の結晶の定量的析出が退れる樣である。 $10^{\circ} \mathrm{C}$ 位の室溫で行う場合一畫夜 の放置では定量的には行われ難い。又, 液量に對する筬酸 Hydroxylamine の濃度は必ずしも1\%になるよ 5に入れなくとも定量にはさしたる影響はないが濾液中に溶ける量は泱度が高いと少く $1 \%$ の場合定量的に 結晶をつくりやすいようである。

\section{II. 仕込方法を別にするもろみ中の Diacetyl について}

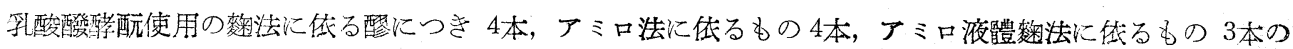
酰につき, 㴗液 $10 l$ 中の Diacetyl を定量した。

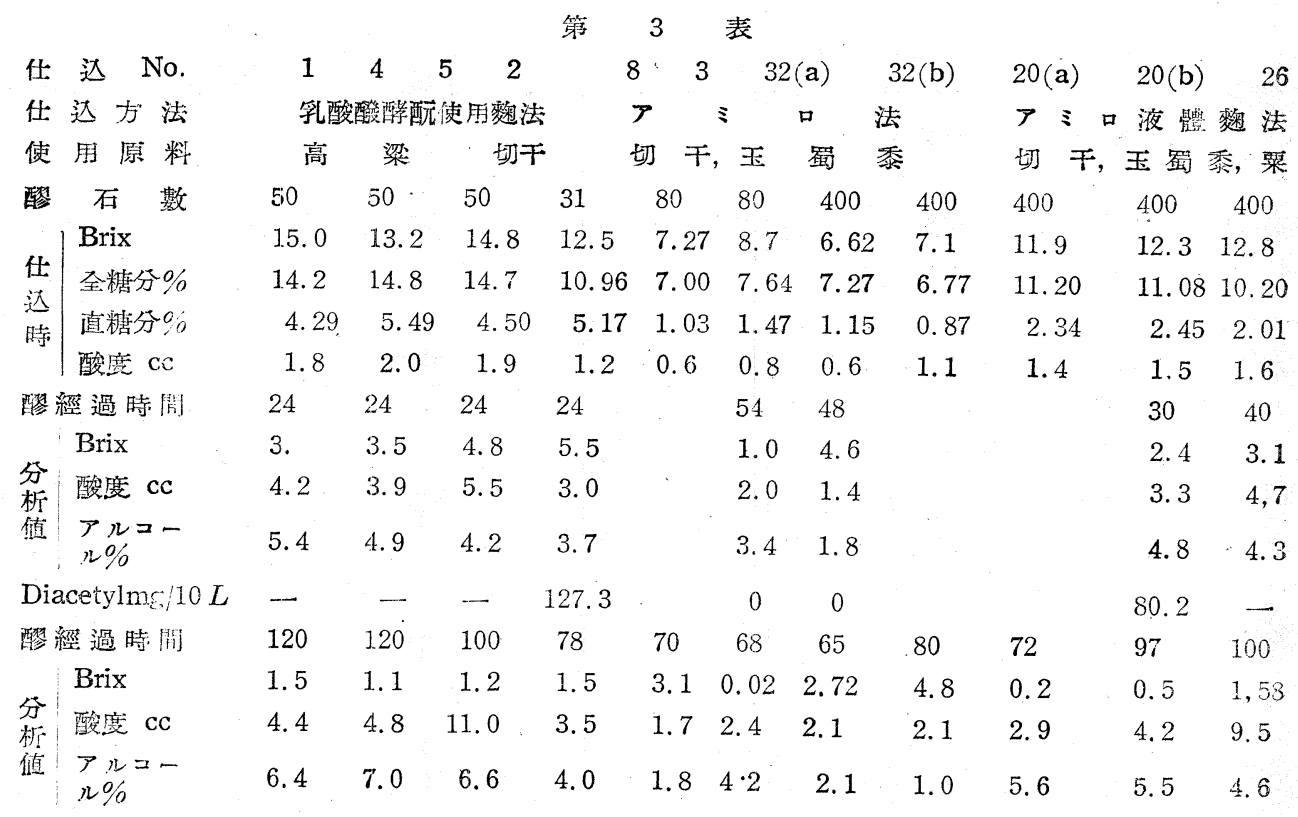

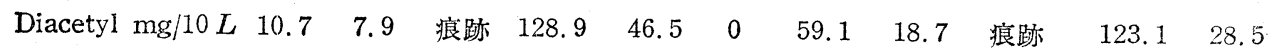

酪の Diacetyl は 0 0.001289\% で定量を行つたものの本均は $0.000538 \%$ である。仕达方法の別に供つ てはその差異を認められない。又, 酸度の多く增加した No. 5 及び 26 では痕跡乃至 $0.000285 \%$ で必ずし も多くなく，檢出されなからたものとしてはアミロ法低る No.3 のみであつた。

III. むろみより分離した菌の性質と Voges Proskauer 反應について

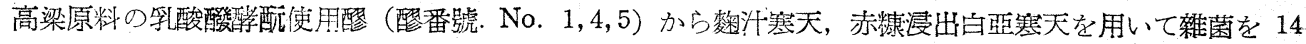

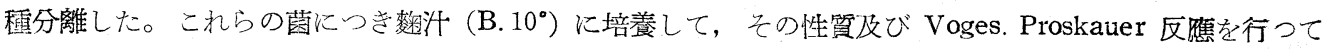

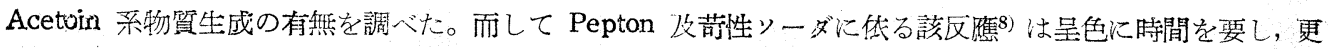

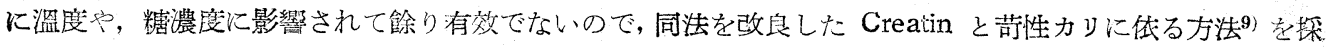


41 ( 401$)$ J. 60

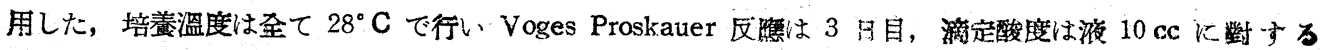
$1 / 10 \mathrm{~N} \cdot \mathrm{NaOH}$ 滴定數で 7 日目のものである。

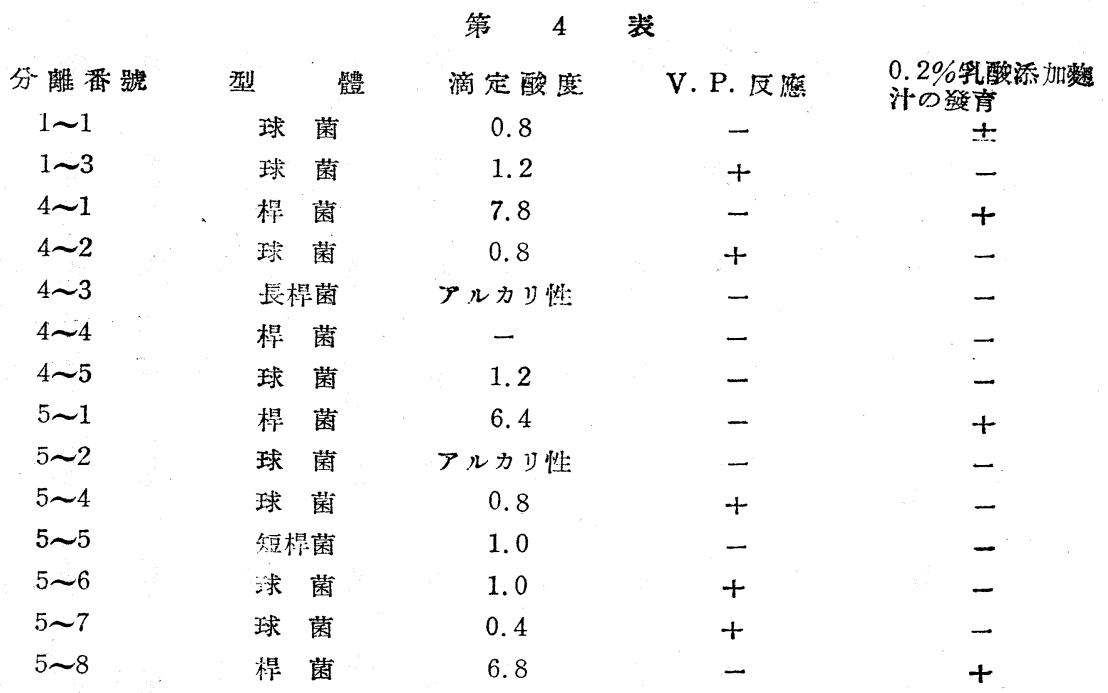

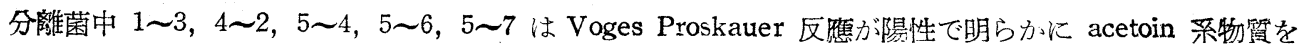
生成するものであるが $0.2 \%$ 乳酸添加麴汁に於いては發育せず, 孚酸菌と思われる 4〜1, 5 1, 5 8 のみ 發育する。刃 1〜1 は僅かに發育する丈で，他は全て發育しない。

摘要

1 アルコール製品のつわり香の原因となる Diacetyl の成因を確かめんとして醪の Diacetyl をVan Niel 法で定量した。而して Van Niel 法では定量條件にアルコール濃度溫度及び溶液中の監酸 hydroxylamine 濃度がぞの樣に影響するか豫備璂驗を行つた。その結果

(1). アルコール度數 70 度の子のまでにはその影響は見られない。

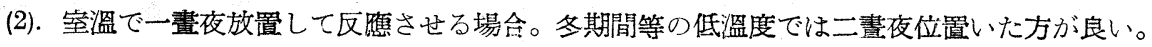

(3). 籃酸 Hydroxylamine の液中の濃度は必ずしも $1 \%$ となるように加えなくてもよいが，濃いと定量的 に結晶をつくりやすい。

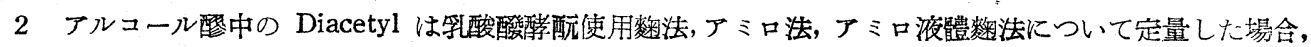
仕达方法に低る美異は認められなかつた。アミロ法に低るものの5ち1本文檢出されず他は本均 $0.000538 \%$

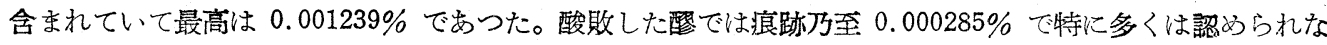
からた。

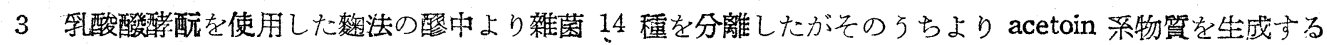
Voges Proskauer 反應陽性のものが 4 種あつた。併しこれらのものは $0.2 \%$ 乳酸添加畨汁中では發育し なかつた。

\section{引用 交 獻}

1). 富安行雄：農化 14. 160 。昭 13

2). Harden: Pro. Roy. Society 77. 424. 1906

3). C. Neubergu. E. Reinfurth: Bioch. Zeitsch., 143. 553 565. 1923

4). 北原覺雄, 福井作藏：酸醉工學 28.11 14 昭 25

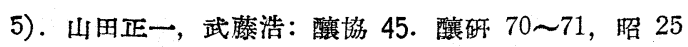

6). C. B.Van Niel: Bioch. Zeitsch., 187. 472, 1927

7). 富安行雄：農化 13.787. 炤 12

8). 富安行雄：農化 14 . 昭 13

9). S.S.Epstein, Max Levine: C.A. 29. 2570. 1935 


\section{Studies on Diacetyl Part III}

Diacetyl in moromi-mash of alcohol

\section{By}

\section{Shirô HanaI and Masakazu Yamada}

(Received. Aug. 7, 1951)

I On the Van Niel method for estimating diacetyl content.

1. $0 \sim 70 \%$ of alcohol in the solution shows no influence on the estimation of diacetyl.

2. The reaction should be continued for 48 hours rather than for 24 hours in winter.

3. The concentration of the hydroxylamine- $\mathrm{HCl}$ reagent need not be over $1 \%$, but the more concentrated is the reagent, the easier is the formation of crystal for quantitative determination.

II Diacetyl in moromi-mash of alcohol.

Tne moromi-mashes of various types, such as of the kojii-method accompanying lactic acid fermentation, the amylo-method and a blending of the amylo and liquid-kōji (submerged culture of Asp. oryzae) methods, contain diacetyl 0 0.0001289\%, on average.

Even when the mashes incline sour, diacetyl does not always increase in parallel.

Such mashes contain diacetyl from trace to $0.000285 \%$.

\section{Diacetyl に關する研究（第四報）}

\section{不純アルコロルより Diacetyl の囩收}

山田正一, 花井四 郎

(昭相 26 年 8 月 7 日受理)

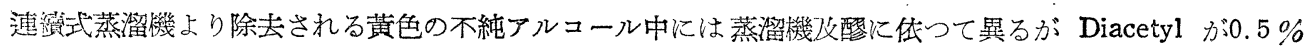
愔舍まれている。此の Diacetyl は香料として煙草やマーガリン等に使用されて居るが現在は合成に低つて のみ造られているに過ぎない。この不純アルコールを香料として直接利用する事はメチルアルコール濃度が 高いため不可能である。この副成される不純アルコールは 95\% アルコールに對し 2 0.3\% 位で全國的に

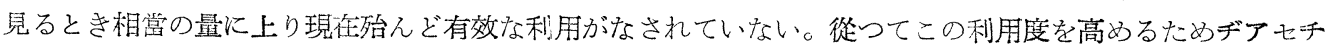

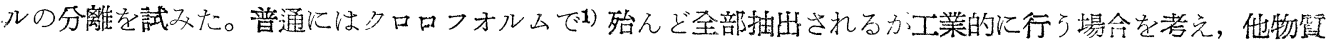
之結合させてアルコール分と分離して後 Diacetyl を取り出す方法を行つた。

デアセチルの性質としては2,3)，4,35) アルカリ性で重合して褐色粘稠性物質になる。郎ち

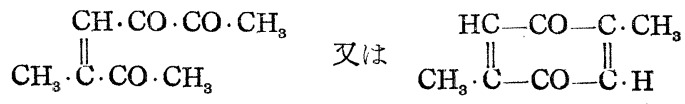

腹水雷合するものであり，双アンモニアとは Trimethylglyoxalin をつくる。

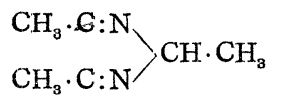

アルコール溶液では aniline と反應して, 板狀結晶の dianil をつくる。

$$
\begin{aligned}
& \mathrm{CH}_{3} \cdot \mathrm{C}: \mathrm{NC}_{8} \mathrm{H}_{5} \\
& \mathrm{CH}_{3} \cdot \mathrm{C}: \mathrm{NC}_{8} \mathrm{H}_{5}
\end{aligned}
$$

家に o-diamine ${ }^{6)}$ と反潐して chinoxalin の結晶をつくることや hydroxylamine と反應して oxime， phenyihydrazine と反應して hydrazone 又コは osazone を酸性亞硫酸ッーダと反應すること等が知られて 